\title{
Comparison of Tumor Volumes Derived from Glucose Metabolic Rate Maps and SUV Maps in Dynamic ${ }^{18}$ F-FDG PET
}

Eric P. Visser ${ }^{1}$, Mariëlle E.P. Philippens ${ }^{2}$, Laura Kienhorst ${ }^{1}$, Johannes H.A.M. Kaanders ${ }^{2}$, Frans H.M. Corstens ${ }^{1}$, Lioe-Fee de Geus-Oei ${ }^{1}$, and Wim J.G. Oyen ${ }^{1}$

${ }^{1}$ Department of Nuclear Medicine, Radboud University Nijmegen Medical Centre, Nijmegen, The Netherlands; and ${ }^{2}$ Department of Radiation Oncology, Radboud University Nijmegen Medical Centre, Nijmegen, The Netherlands

Tumor delineation using noninvasive medical imaging modalities is important to determine the target volume in radiation treatment planning and to evaluate treatment response. It is expected that combined use of CT and functional information from ${ }^{18} \mathrm{~F}-\mathrm{FDG}$ PET will improve tumor delineation. However, until now, tumor delineation using PET has been based on static images of ${ }^{18} \mathrm{~F}$ FDG standardized uptake values (SUVs). ${ }^{18} \mathrm{~F}-\mathrm{FDG}$ uptake depends not only on tumor physiology but also on blood supply, distribution volume, and competitive uptake processes in other tissues. Moreover, ${ }^{18} \mathrm{~F}-\mathrm{FDG}$ uptake in tumor tissue and in surrounding healthy tissue depends on the time after injection. Therefore, it is expected that the glucose metabolic rate $\left(\mathrm{MR}_{\mathrm{glu}}\right)$ derived from dynamic PET scans gives a better representation of the tumor activity than does SUV. The aim of this study was to determine tumor volumes in $\mathrm{MR}_{\mathrm{glu}}$ maps and to compare them with the values from SUV maps. Methods: Twenty-nine lesions in 16 dynamic ${ }^{18} \mathrm{~F}-\mathrm{FDG}$ PET scans in 13 patients with non-small cell lung carcinoma were analyzed. $\mathrm{MR}_{\text {glu }}$ values were calculated on a voxel-by-voxel basis using the standard 2-compartment ${ }^{18} \mathrm{~F}-\mathrm{FDG}$ model with trapping in the linear approximation (Patlak analysis). The blood input function was obtained by arterial sampling. Tumor volumes were determined in SUV maps of the last time frame and in $\mathrm{MR}_{\text {glu }}$ maps using 3-dimensional isocontours at $50 \%$ of the maximum SUV and the maximum $\mathrm{MR}_{\text {glu }}$, respectively. Results: Tumor volumes based on SUV contouring ranged from 1.31 to $52.16 \mathrm{~cm}^{3}$, with a median of $8.57 \mathrm{~cm}^{3}$. Volumes based on $\mathrm{MR}_{\text {glu }}$ ranged from 0.95 to $37.29 \mathrm{~cm}^{3}$, with a median of $3.14 \mathrm{~cm}^{3}$. For all lesions, the $\mathrm{MR}_{\mathrm{glu}}$ volumes were significantly smaller than the SUV volumes. The percentage differences (defined as $100 \% \times\left(\mathrm{V}_{\mathrm{MR}_{\text {glu }}}-\mathrm{V}_{\mathrm{SUV}}\right) / \mathrm{V}_{\mathrm{SuV}}$, where $\mathrm{V}$ is volume) ranged from $-12.8 \%$ to $-84.8 \%$, with a median of $-32.8 \%$. Conclusion: Tumor volumes from $\mathrm{MR}_{\text {glu }}$ maps were significantly smaller than SUV-based volumes. These findings can be of importance for PET-based radiotherapy planning and therapy response monitoring.

Received Dec. 10, 2007; revision accepted Feb. 26, 2008.

For correspondence contact: Eric P. Visser, Department of Nuclear Medicine (internal postal code 444), Radboud University Nijmegen Medical Centre, P.O. Box 9101, 6500 HB Nijmegen, The Netherlands.

E-mail: e.visser@nucmed.umcn.nl

COPYRIGHT @ 2008 by the Society of Nuclear Medicine, Inc.
Key Words: dynamic PET; FDG; SUV; glucose metabolic rate; NSCLC

J Nucl Med 2008; 49:892-898

DOI: 10.2967/jnumed.107.049585

$\mathbf{T}$ umor delineation using noninvasive medical imaging modalities is important to determine the target volume in radiation treatment planning and to evaluate treatment response. It is expected that the combined use of CT and the functional information from ${ }^{18} \mathrm{~F}-\mathrm{FDG}$ PET will lead to improved tumor delineation (1-9). However, until now, tumor delineation using PET has been based on static images of ${ }^{18} \mathrm{~F}-\mathrm{FDG}$ uptake obtained at a fixed time after injection.

${ }^{18}$ F-FDG uptake can be expressed in activity concentration values (e.g., $\mathrm{Bq} / \mathrm{cm}^{3}$ ), directly available from the PET images, or in standardized uptake values $\left(\mathrm{SUV}, \mathrm{g} / \mathrm{cm}^{3}\right.$ ), where the activity concentration has been corrected for the administered activity and the estimated distribution volume, and sometimes for the plasma glucose concentration. However, when tumor volumes are calculated using isocontours at a fixed percentage of the maximum uptake within the tumor, both images are equivalent because in each PET scan, activity concentration and SUV differ only by a fixed multiplicative constant. For consistency throughout this paper, uptake values will be expressed as SUV using

$$
\mathrm{SUV}=\frac{\mathrm{C}_{\mathrm{FDG}} \times \mathrm{m}_{\mathrm{b}}}{\mathrm{A}_{\mathrm{adm}}}
$$

with $\mathrm{C}_{\mathrm{FDG}}$ the activity concentration in (tumor) tissue $\left(\mathrm{Bq} / \mathrm{cm}^{3}\right), \mathrm{A}_{\mathrm{adm}}$ the administered activity $(\mathrm{Bq})$, and $\mathrm{m}_{\mathrm{b}}$ the patient's body mass $(\mathrm{g})$.

${ }^{18}$ F-FDG uptake depends not only on the tumor physiology and tumor cell density but also on the blood supply, the distribution volume, and competitive uptake processes in other tissues. Moreover, the uptake of ${ }^{18} \mathrm{~F}-\mathrm{FDG}$ in tumor tissue and in surrounding healthy tissue is time-dependent, because even at $1 \mathrm{~h}$ after injection, which is the normal scan 
starting time in static, whole-body ${ }^{18}$ F-FDG PET, tumors still accumulate ${ }^{18}$ F-FDG. Accordingly, the distribution of ${ }^{18} \mathrm{~F}-\mathrm{FDG}$ over the tumor and its surroundings will change with time and will, in general, differ from tumor to tumor and from patient to patient.

In contrast, the glucose metabolic rate $\left(\mathrm{MR}_{\mathrm{glu}}\right)$, defined as the rate at which glucose is being metabolized (expressed, for example, in $\mu \mathrm{mol} /\left[\mathrm{cm}^{3} \times \mathrm{min}\right]$ of tissue), is not influenced by these processes and parameters. In the standard 2-compartment ${ }^{18} \mathrm{~F}$-FDG model with trapping in the linear approximation (Patlak analysis) $(10,11)$,

$$
\mathrm{MR}_{\mathrm{glu}}=\frac{\mathrm{K}_{1} \mathrm{k}_{3}}{\mathrm{k}_{2}+\mathrm{k}_{3}} \mathrm{C}_{\mathrm{p}, \mathrm{glu}}=\mathrm{K}_{\mathrm{i}} \mathrm{C}_{\mathrm{p}, \mathrm{glu}}
$$

where $\mathrm{K}_{1}, \mathrm{k}_{2}$, and $\mathrm{k}_{3}$ are the 3 rate constants of the 2-compartment model, $\mathrm{K}_{\mathrm{i}}$ is the ${ }^{18} \mathrm{~F}$-FDG influx constant, and $\mathrm{C}_{\mathrm{p}, \mathrm{glu}}$ is the plasma glucose concentration. The linear approximation is valid when the plasma ${ }^{18} \mathrm{~F}-\mathrm{FDG}$ concentration changes slowly and the data points in the Patlak curve approach a straight line with the slope equal to $\mathrm{K}_{\mathrm{i}}$ (11). Equation 2 shows that $\mathrm{MR}_{\text {glu }}$ depends only on the tissue microparameters $\mathrm{K}_{1}$ (rate constant for transport of free ${ }^{18} \mathrm{~F}$-FDG from plasma to tissue), $\mathrm{k}_{2}$ (rate constant for transport of free ${ }^{18} \mathrm{~F}-\mathrm{FDG}$ back into plasma), $\mathrm{k}_{3}$ (rate constant for phosphorylation of ${ }^{18} \mathrm{~F}$-FDG inside the cell), and $\mathrm{C}_{\mathrm{p}, \mathrm{glu}}$, which is approximately constant during the PET scan when patients are fasting. Therefore, it is expected that $\mathrm{MR}_{\mathrm{glu}}$ derived from dynamic PET scans better represents the tumor metabolic activity than does SUV. The aim of this study was to determine tumor volumes based on $\mathrm{MR}_{\mathrm{glu}}$ maps and to compare them with the values from SUV maps. Tumor volumes determined by isocontouring in $\mathrm{MR}_{\mathrm{glu}}$ maps will not be influenced by constant multiplicative factors. Therefore, the same tumor volumes would be obtained using $\mathrm{K}_{\mathrm{i}}$ maps, which differ from $\mathrm{MR}_{\mathrm{glu}}$ maps by the plasma glucose concentration. For consistency throughout this paper, we will use $\mathrm{MR}_{\mathrm{glu}}$ maps and report maximum and average $\mathrm{MR}_{\mathrm{glu}}$ values within lesions.

\section{MATERIALS AND METHODS}

\section{Patients}

Twenty-nine lesions in 16 dynamic ${ }^{18}$ F-FDG PET scans of 13 patients (11 men and 2 women) with non-small cell lung carcinoma were analyzed. The mean patient age was 65 y (range, 5275 y). Patients with diabetes mellitus were excluded. The PET scans were performed as part of a response monitoring study (12), which was approved by the Institutional Review Board of the Radboud University Nijmegen Medical Centre. Written informed consent was obtained from all patients.

\section{PET Image Acquisition and Reconstruction}

Patients fasted for at least $6 \mathrm{~h}$. Cannulas were inserted in an antecubital vein for ${ }^{18}$ F-FDG injection and in a radial artery (20gauge cannula) for blood sampling. The blood glucose level was within the normal range in all patients (hexokinase method [Aeroset]; Abbott Diagnostics).
All scans were acquired on an ECAT EXACT47 scanner (Siemens/CTI) in septa-extended (2-dimensional) mode. After a 20 -min transmission scan using the built-in ${ }^{68} \mathrm{Ge}$ transmission sources, 200-250 MBq of ${ }^{18}$ F-FDG were injected intravenously over a 1-min period followed by a $40-\mathrm{mL}$ saline flush at a rate of 8 $\mathrm{mL} / \mathrm{s}$, using an infusion pump (Medrad). Dynamic data acquisition began simultaneously with ${ }^{18} \mathrm{~F}$-FDG injection for 16 time frames $(10 \times 30 \mathrm{~s}, 3 \times 300 \mathrm{~s}$, and $3 \times 600 \mathrm{~s})$ for a total time of $50 \mathrm{~min}$. Images were corrected for radioactive decay, attenuation, and randoms. Scatter correction based on measured scatter fractions as implemented in the ECAT 7.2.1 software was used. Attenuationcorrected images were reconstructed in $128 \times 128 \times 47$ matrices using 2-dimensional ordered-subsets expectation maximization with Fourier rebinning (4 iterations and 16 subsets). A zoom factor of 1.5 in the transaxial direction, and a Gauss filter of $5 \mathrm{~mm}$ in both the transaxial and the axial directions, were used. The resulting voxel size was $3.432 \times 3.432 \times 3.375 \mathrm{~mm}$. The axial field of view was $16.2 \mathrm{~cm}$.

\section{Arterial Plasma Input Function}

Immediately after ${ }^{18}$ F-FDG injection, 7 arterial blood samples $(2 \mathrm{~mL})$ were drawn at 15 -s intervals, followed by samples at $135 \mathrm{~s}$, $165 \mathrm{~s}, 225 \mathrm{~s}, 285 \mathrm{~s}, 7.5 \mathrm{~min}, 12.5 \mathrm{~min}, 17.5 \mathrm{~min}, 25 \mathrm{~min}, 35 \mathrm{~min}$, and $45 \mathrm{~min}$ after injection. Plasma radioactivity was determined in a well-type $\gamma$-counter (Wallac 1480 Wizard; Perkin Elmer Lifescience) using the standard solution method (13).

\section{MR $_{\text {glu }}$ Images}

$\mathrm{MR}_{\mathrm{glu}}$ values were calculated on a voxel-by-voxel basis using the standard 2-compartment ${ }^{18} \mathrm{~F}$-FDG model with trapping in the linear approximation according to Equation 2. For all tumors investigated, the Patlak curves approached a straight line at approximately $10-15 \mathrm{~min}$ after injection. Therefore, $\mathrm{MR}_{\mathrm{glu}}$ was determined by linear least-squares fitting of the last 5 time frames of the dynamic dataset - that is, for the interval of 10-50 min after injection. Because the Patlak analysis was done on a voxelby-voxel basis, 3-dimensional volumes of $\mathrm{MR}_{\mathrm{glu}}$ values, or $\mathrm{MR}_{\mathrm{glu}}$ maps, were obtained.

\section{Tumor Contouring}

Tumor volumes were determined in SUV maps of the last time frame (40-50 min after injection) and in $\mathrm{MR}_{\text {glu }}$ maps using 3-dimensional isocontours at $50 \%$ of the maximum SUV and the maximum $\mathrm{MR}_{\mathrm{glu}}$, respectively. Only lesions for which the $50 \%$ isocontours were completely within the $16.2-\mathrm{cm}$ axial field of view of the scanner were analyzed.

\section{Tumor-to-Background (T/B) Ratios}

For lesions that were in the lung (as opposed to in the mediastinum, in the ribs, or subcutaneous), and that were surrounded by a more or less uniform background region, 3-dimensional lung background regions were drawn to represent the SUV and $\mathrm{MR}_{\text {glu }}$ in healthy lung tissue. Fourteen of the 29 lesions fulfilled this criterion. For these lesions, the T/B, defined as the average lesion value (based on the 50\% 3-dimensional isocontours) divided by the average background value, were determined in both the SUV maps and the $\mathrm{MR}_{\mathrm{glu}}$ maps.

\section{Statistical Fluctuations in MR $_{\text {glu }}$ and SUV Voxel Values}

Tumor volumes determined by isocontouring at a fixed percentage of the maximum voxel value of SUV and $\mathrm{MR}_{\text {glu }}$ are influenced by statistical fluctuations of these maximum values. If 
the $\mathrm{MR}_{\mathrm{glu}}$ images are noisier than the SUV images, the average result will be too-large $\mathrm{MR}_{\text {glu }}$ values for the tumor maximum and, accordingly, too-small lesion sizes because the 50\% threshold effectively has then shifted to higher values and can no longer be compared with the $50 \%$ SUV threshold. To estimate these statistical fluctuations, we determined the standard deviation (SD) in SUV and $\mathrm{MR}_{\mathrm{glu}}$ for clusters of voxels around the tumor maximum for each lesion. The voxel clusters consisted of the voxel of maximum intensity and its 4 adjacent voxels in the same transaxial plane. Of course, these SDs will also partly contain the real differences in the parameter values as determined by the tumor heterogeneity, but they can serve as upper limits to the statistical fluctuations and can be used to compare the statistical noise in SUV and $\mathrm{MR}_{\text {glu }}$ maps.

\section{RESULTS}

The results of the tumor contouring are summarized in Table 1. All lesions showed smaller $\mathrm{MR}_{\mathrm{glu}}$-based volumes than SUV-based volumes. Figure 1 compares both types of tumor volumes on a lesion-by-lesion basis. The average SUVs within the lesions ranged from 2.26 to $9.20 \mathrm{~g} / \mathrm{cm}^{3}$. The SUV-based tumor volumes ranged from 1.31 to 52.16 $\mathrm{cm}^{3}$, with a median of $8.57 \mathrm{~cm}^{3}$. The $\mathrm{MR}_{\mathrm{glu}}$-based volumes were significantly smaller, with a range from 0.95 to 37.29 $\mathrm{cm}^{3}$ and a median of $3.14 \mathrm{~cm}^{3}(P<0.0001$, Wilcoxon signed rank test). The percentage differences (defined as $100 \% \times\left(\mathrm{V}_{\mathrm{MR}_{\text {glu }}}-\mathrm{V}_{\mathrm{SUV}}\right) / \mathrm{V}_{\mathrm{SUV}}$, where $\mathrm{V}$ is volume $)$ ranged from $-12.8 \%$ to $-84.8 \%$, with a median of $-32.8 \%$.

An example of typical cross-sectional profiles of SUV and $\mathrm{MR}_{\text {glu }}$ through a lesion is shown in Figure 2 (patient 2, scan 1, lesion 1). The tumor is smaller in the $\mathrm{MR}_{\text {glu }}$ profile than in the SUV profile. Moreover, the SUV background relative to the tumor maximum is higher than the $\mathrm{MR}_{\mathrm{glu}}$ background relative to the maximum. The lesion and background data and the T/Bs based on SUV and $\mathrm{MR}_{\text {glu }}$ are presented in Table 2. Figure 3 summarizes the T/Bs on a lesion-by-lesion basis. All T/Bs were significantly lower for SUV than for $\mathrm{MR}_{\mathrm{glu}}(P<0.0001$, Wilcoxon signed rank test). For SUV, T/B ranged from 5.6 to 20.9, with a median of 11.4. For $\mathrm{MR}_{\mathrm{glu}}, \mathrm{T} / \mathrm{B}$ ranged from 23.9 to 113.7, with a median of 51.4 .

Figure 4 shows the results of the analysis of statistical fluctuations of the maximum voxel values as explained in

TABLE 1

Overview of Lesion Characteristics

\begin{tabular}{|c|c|c|c|c|c|c|c|c|}
\hline Patient & Scan & Lesion & $\begin{array}{c}\text { Average } \\
\text { SUV }\left(\mathrm{g} / \mathrm{cm}^{3}\right)\end{array}$ & $\begin{array}{c}\text { Maximum } \\
\text { SUV }\left(\mathrm{g} / \mathrm{cm}^{3}\right)\end{array}$ & $\begin{array}{c}\text { Average } \mathrm{MR}_{\mathrm{glu}} \\
\left(\mu \mathrm{mol} /\left[\mathrm{cm}^{3} \times \mathrm{min}\right]\right)\end{array}$ & $\begin{array}{l}\text { SUV-based } \\
\text { volume }\left(\mathrm{cm}^{3}\right)\end{array}$ & $\begin{array}{l}\mathrm{MR}_{\mathrm{glu}} \text {-based } \\
\text { volume }\left(\mathrm{cm}^{3}\right)\end{array}$ & $\begin{array}{l}\text { Difference in } \\
\left.\text { volumes* }^{*} \%\right)\end{array}$ \\
\hline 1 & 1 & 1 & 7.23 & 10.70 & 0.200 & 11.01 & 8.59 & -22.0 \\
\hline \multirow[t]{4}{*}{2} & 1 & 1 & 3.70 & 6.06 & 0.126 & 36.02 & 13.87 & -61.5 \\
\hline & & 2 & 4.08 & 6.10 & 0.119 & 5.25 & 3.14 & -40.2 \\
\hline & & 3 & 2.79 & 4.29 & 0.084 & 3.78 & 2.58 & -31.6 \\
\hline & & 4 & 2.83 & 4.33 & 0.085 & 2.42 & 1.63 & -32.8 \\
\hline \multirow[t]{4}{*}{3} & 1 & 1 & 3.29 & 4.97 & 0.073 & 2.31 & 1.39 & -39.7 \\
\hline & & 2 & 2.80 & 4.14 & 0.058 & 1.51 & 1.03 & -31.6 \\
\hline & & 3 & 4.92 & 7.22 & 0.119 & 1.83 & 1.27 & -30.4 \\
\hline & & 4 & 2.82 & 4.25 & 0.066 & 1.95 & 0.95 & -51.0 \\
\hline \multirow[t]{2}{*}{4} & 1 & 1 & 6.71 & 10.46 & 0.185 & 27.35 & 18.56 & -32.1 \\
\hline & 2 & 1 & 4.59 & 7.32 & 0.148 & 14.47 & 8.47 & -41.5 \\
\hline 5 & 2 & 1 & 6.62 & 10.52 & 0.161 & 32.28 & 23.81 & -26.2 \\
\hline 6 & 1 & 1 & 5.80 & 8.90 & 0.152 & 8.86 & 6.76 & -23.8 \\
\hline \multirow[t]{3}{*}{7} & 1 & 1 & 3.91 & 5.96 & 0.100 & 4.37 & 2.54 & -41.8 \\
\hline & & 2 & 4.52 & 7.22 & 0.131 & 42.06 & 33.03 & -21.5 \\
\hline & & 3 & 3.45 & 5.42 & 0.079 & 5.41 & 2.82 & -47.8 \\
\hline \multirow[t]{2}{*}{8} & 1 & 1 & 5.93 & 9.20 & 0.178 & 6.28 & 2.58 & -58.9 \\
\hline & & 2 & 4.30 & 7.11 & 0.115 & 9.18 & 1.39 & -84.8 \\
\hline \multirow[t]{3}{*}{9} & 1 & 1 & 3.12 & 4.64 & 0.081 & 3.26 & 1.95 & -40.2 \\
\hline & & 2 & 2.57 & 3.93 & 0.073 & 4.49 & 2.78 & -38.1 \\
\hline & & 3 & 2.26 & 3.32 & 0.080 & 1.31 & 0.99 & -24.2 \\
\hline \multirow[t]{2}{*}{10} & 1 & 1 & 4.90 & 7.67 & 0.167 & 46.27 & 30.09 & -35.0 \\
\hline & 2 & 1 & 3.37 & 5.19 & 0.086 & 8.75 & 4.02 & -54.1 \\
\hline \multirow[t]{2}{*}{11} & 1 & 1 & 6.21 & 9.54 & 0.203 & 14.91 & 13.00 & -12.8 \\
\hline & 2 & 1 & 4.15 & 6.34 & 0.097 & 20.19 & 9.38 & -53.5 \\
\hline \multirow[t]{2}{*}{12} & 1 & 1 & 9.20 & 14.30 & 0.292 & 27.11 & 20.04 & -26.1 \\
\hline & & 2 & 9.12 & 14.48 & 0.284 & 40.07 & 27.87 & -30.5 \\
\hline \multirow[t]{2}{*}{13} & 1 & 1 & 7.96 & 12.93 & 0.286 & 52.16 & 37.29 & -28.5 \\
\hline & & 2 & 4.31 & 6.84 & 0.130 & 1.31 & 0.99 & -24.2 \\
\hline Median & & & 4.30 & 6.84 & 0.119 & 8.75 & 3.14 & -32.8 \\
\hline
\end{tabular}




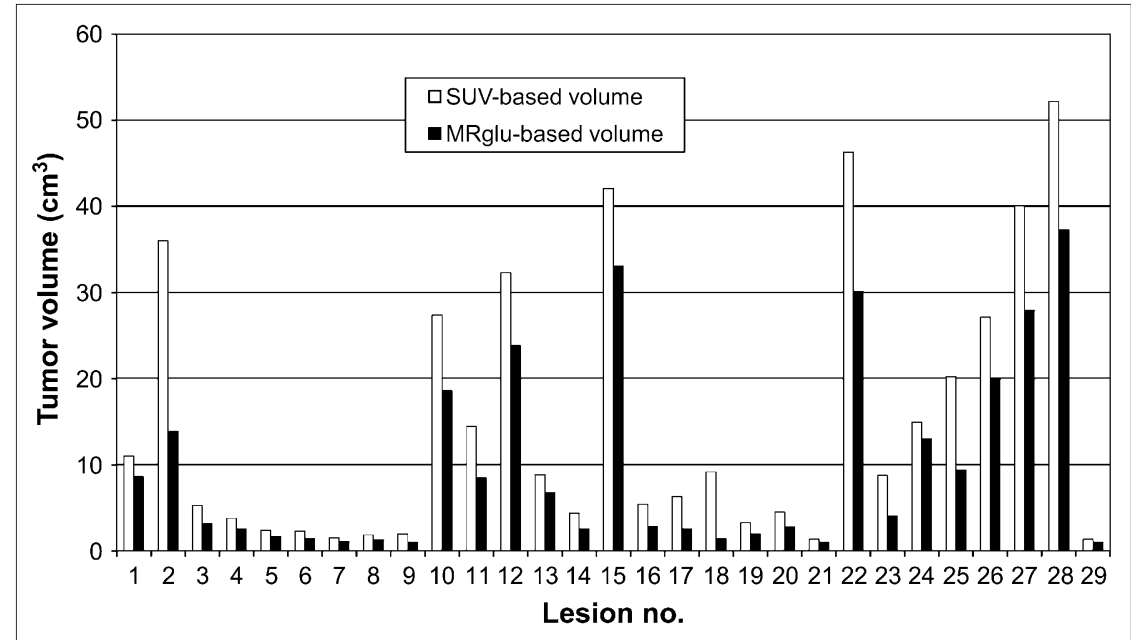

FIGURE 1. Comparison of SUV-based and $\mathrm{MR}_{\mathrm{glu}}$-based tumor volumes on lesion-by-lesion basis. Results are displayed in same order as in Table 1. the preceding section. The relative SD for SUV and $\mathrm{MR}_{\mathrm{glu}}$ are defined as the SD within the voxel clusters divided by the maximum voxel value. The averaged relative SD for SUV and $\mathrm{MR}_{\mathrm{glu}}$ over all lesions equaled 0.090 and 0.108 , respectively.

\section{DISCUSSION}

This study demonstrated that tumors in $\mathrm{MR}_{\mathrm{glu}}$ images are smaller and have sharper borders than do tumors in SUV images and that background intensities are higher in SUV images than in $\mathrm{MR}_{\text {glu }}$ images. In other words, $\mathrm{MR}_{\mathrm{glu}}$ images are richer in contrast than are SUV images. An obvious reason for the greater background signals in SUV images is that SUV signals consist not only of trapped or metabolizing ${ }^{18} \mathrm{~F}-\mathrm{FDG}$ but also of free, nonmetabolized, ${ }^{18} \mathrm{~F}-\mathrm{FDG}$, present in, for example, blood vessels or the intercellular space. These greater SUV background values can, at least partly, explain the larger tumor volumes in

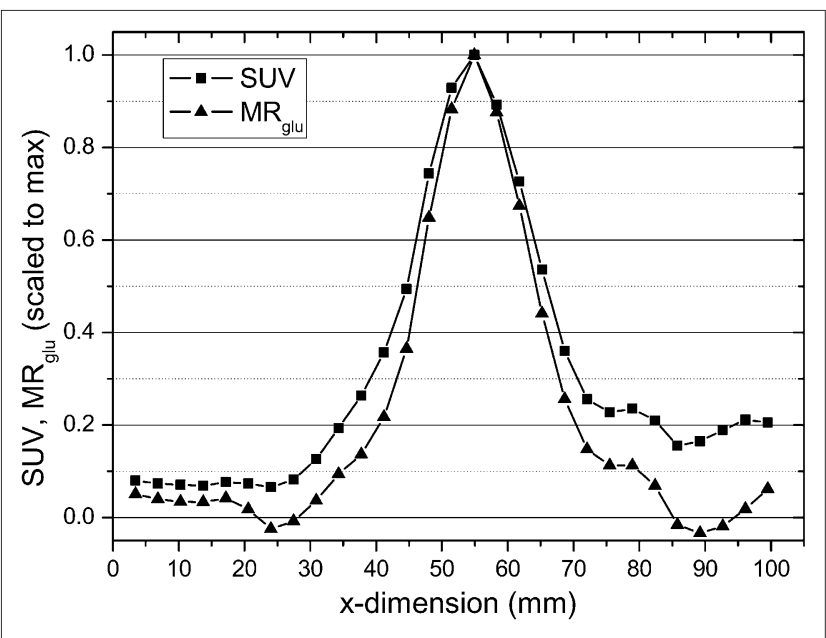

FIGURE 2. Typical cross-sectional profiles of SUV and MR $\mathrm{Mlu}_{\mathrm{glu}}$ through a lesion (patient 2, scan 1, lesion 1). For direct comparison, maxima of both profiles have been scaled to 1 .
SUV images than in $\mathrm{MR}_{\text {glu }}$ images. When a background signal is superimposed on a lesion signal, an isocontour at a fixed percentage of the maximum tumor value will enclose a larger region than when no background is present. This effect is illustrated in Figure 5, where simplified cross sections of a tumor are shown for SUV and $\mathrm{MR}_{\mathrm{glu}}$. The SUV tumor profile is chosen to be superimposed on a relatively high background signal, whereas the $\mathrm{MR}_{\text {glu }}$ profile has a low or negligible background. The tumor sizes, indicated by the double arrows, are based on $50 \%$ of the maximum lesion value (full width at half maximum).

We performed the same analyses using different isocontour level settings $(40 \%, 60 \%, 70 \%$, and $80 \%)$. These analyses confirmed the conclusion that tumor volumes are significantly smaller from $\mathrm{MR}_{\mathrm{glu}}$ maps than from SUV maps (data available on file).

In Equation 2, the lumped constant (LC), accounting for the difference in affinity between glucose and ${ }^{18} \mathrm{~F}$-FDG to glucose transporters and the phosphorylating system, was set to 1 . Further, the fractional blood volume in the tumor, $\mathrm{V}_{\mathrm{B}}$, was neglected. If this had not been the case, $\mathrm{MR}_{\mathrm{glu}}$ values would have changed according to

$$
\mathrm{MR}_{\mathrm{glu}}^{\prime}=\frac{\mathrm{LC}}{1-\mathrm{V}_{\mathrm{B}}} \mathrm{MR}_{\mathrm{glu}}
$$

However, when $\mathrm{V}_{\mathrm{B}}$ and $\mathrm{LC}$ are assumed to be more or less constant throughout a tumor, the resulting $\mathrm{MR}_{\mathrm{glu}}$ volumes are not affected, because all voxel values in the $\mathrm{MR}_{\mathrm{glu}}$ map would have been multiplied by the same constant factor. To our knowledge, no human studies have been performed with regard to LC outside the central nervous system, and ${ }^{18} \mathrm{~F}$ FDG PET studies dealing with the spatial distribution of $V_{B}$ across lung tumors are not available.

Because of the finite spatial resolution of the scanner, the influence of the partial-volume effect on the contouring results should be considered. With an effective linear spatial resolution of about $6 \mathrm{~mm}(14)$, the volumetric resolution 
TABLE 2

Overview of T/B Characteristics

\begin{tabular}{|c|c|c|c|c|c|c|c|c|c|}
\hline Patient & Scan & Lesion & $\begin{array}{l}\text { Size of lung } \\
\text { background } \\
\left(\mathrm{cm}^{3}\right)\end{array}$ & $\begin{array}{c}\text { Average } \\
\text { SUV in } \\
\text { lesion }\left(\mathrm{g} / \mathrm{cm}^{3}\right)\end{array}$ & $\begin{array}{c}\text { Average SUV in } \\
\text { lung background } \\
\left(\mathrm{g} / \mathrm{cm}^{3}\right)\end{array}$ & $\begin{array}{c}\text { Average } \mathrm{MR}_{\mathrm{glu}} \\
\text { in lesion } \\
\left(\mu \mathrm{mol} /\left[\mathrm{cm}^{3} \times \mathrm{min}\right]\right)\end{array}$ & $\begin{array}{l}\text { Average } \mathrm{MR}_{\mathrm{glu}} \text { in } \\
\text { lung background } \\
\left(\mu \mathrm{mol} /\left[\mathrm{cm}^{3} \times \mathrm{min}\right]\right)\end{array}$ & $\begin{array}{c}\text { T/B based } \\
\text { on SUV }\end{array}$ & $\begin{array}{c}\text { T/B based } \\
\text { on } \mathrm{MR}_{\mathrm{glu}}\end{array}$ \\
\hline 1 & 1 & 1 & 240.9 & 7.23 & 0.39 & 0.200 & 0.00234 & 18.4 & 85.5 \\
\hline 2 & 1 & 1 & 154.7 & 3.70 & 0.66 & 0.126 & 0.00820 & 5.6 & 15.4 \\
\hline \multirow[t]{2}{*}{4} & 1 & 1 & 148.0 & 6.71 & 0.60 & 0.185 & 0.00282 & 11.3 & 65.4 \\
\hline & 2 & 1 & 145.9 & 4.59 & 0.44 & 0.148 & 0.00130 & 10.6 & 113.7 \\
\hline 6 & 1 & 1 & 154.4 & 5.80 & 0.33 & 0.152 & 0.00306 & 17.4 & 49.6 \\
\hline \multirow[t]{2}{*}{7} & 1 & 1 & 158.2 & 3.91 & 0.39 & 0.100 & 0.00353 & 9.9 & 28.3 \\
\hline & & 2 & 158.2 & 4.52 & 0.39 & 0.131 & 0.00353 & 11.5 & 37.1 \\
\hline 8 & 1 & 2 & 253.2 & 4.30 & 0.31 & 0.115 & 0.00244 & 13.9 & 47.2 \\
\hline 9 & 1 & 3 & 112.6 & 2.26 & 0.36 & 0.080 & 0.00333 & 6.2 & 23.9 \\
\hline \multirow[t]{2}{*}{10} & 1 & 1 & 289.8 & 4.90 & 0.23 & 0.167 & 0.00246 & 20.9 & 67.9 \\
\hline & 2 & 1 & 204.9 & 3.37 & 0.22 & 0.086 & 0.00133 & 15.1 & 64.7 \\
\hline \multirow[t]{2}{*}{11} & 1 & 1 & 152.5 & 6.21 & 0.63 & 0.203 & 0.00381 & 9.8 & 53.3 \\
\hline & 2 & 1 & 152.5 & 4.15 & 0.54 & 0.097 & 0.00336 & 7.7 & 28.9 \\
\hline 12 & 1 & 1 & 207.4 & 9.20 & 0.62 & 0.292 & 0.00492 & 14.9 & 59.4 \\
\hline Median & & & 156.4 & 4.55 & 0.39 & 0.140 & 0.00320 & 11.4 & 51.4 \\
\hline
\end{tabular}

becomes about $0.11 \mathrm{~cm}^{3}$. Although this value is an order of magnitude smaller than the smallest lesion of our study $\left(1.31 \mathrm{~cm}^{3}\right)$, the exact lesion sizes will still differ from the observed ones and can be obtained only by using recovery coefficients based on the scanner resolution, the observed lesion sizes, and the T/Bs (15). However, the Patlak equation

$$
\frac{\mathrm{C}_{\mathrm{tum}}(\mathrm{t})}{\mathrm{C}_{\mathrm{p}}(\mathrm{t})}=\frac{\mathrm{K}_{1} \mathrm{k}_{3}}{\mathrm{k}_{2}+\mathrm{k}_{3}} \frac{\int_{0}^{\mathrm{t}} \mathrm{C}_{\mathrm{p}}(\tau) \mathrm{d} \tau}{\mathrm{C}_{\mathrm{p}}(\mathrm{t})}+\frac{\mathrm{K}_{1} \mathrm{k}_{2}}{\left(\mathrm{k}_{2}+\mathrm{k}_{3}\right)^{2}},
$$

with $\mathrm{C}_{\text {tum }}(\mathrm{t})$ and $\mathrm{C}_{\mathrm{p}}(\mathrm{t})$ the time-dependent tissue and plasma ${ }^{18} \mathrm{~F}-\mathrm{FDG}$ concentrations, respectively, is linear in $\mathrm{C}_{\mathrm{tum}}(\mathrm{t})$, implying that correcting the ${ }^{18} \mathrm{~F}$-FDG uptake in each voxel by scaling factors accounting for the partial-volume effect will lead to $\mathrm{MR}_{\text {glue }}$ voxel values that are scaled by exactly the same factors. Such a correction of course most strongly affects edge voxels in small lesions and has almost no influence on central voxels in large lesions. For tumor isocontouring, more edge voxels will be included within both SUV and $\mathrm{MR}_{\text {glu }}$ isocontours, because several voxels that originally had values lower than $50 \%$ of the tumor maximum have now been raised above this threshold. Both tumor volumes will be increased by roughly the same number of voxels (or cubic centimeters) by the application of partial-volume correction. The reason that this increase in tumor volume is not exactly equal for SUV and $\mathrm{MR}_{\mathrm{glu}}$ lies, of course, in the fact that the distributions of the 2 parameters across a tumor differ. Therefore, our general conclusion that $\mathrm{MR}_{\mathrm{glu}}$-based lesion volumes are significantly smaller than SUV-based volumes will still hold after partial-volume corrections, although the results as shown in Table 1 will quantitatively differ. This conclusion is further confirmed by the fact that large lesions (e.g., $>30 \mathrm{~cm}^{3}$ ), for which the partial-volume effect can definitely be neglected,
FIGURE 3. Comparison of SUV-based and $\mathrm{MR}_{\mathrm{glu}}$-based T/Bs on lesion-bylesion basis. Only lesions for which a uniform background region within lung could be drawn have been selected. Results are displayed in same order as in Table 2.

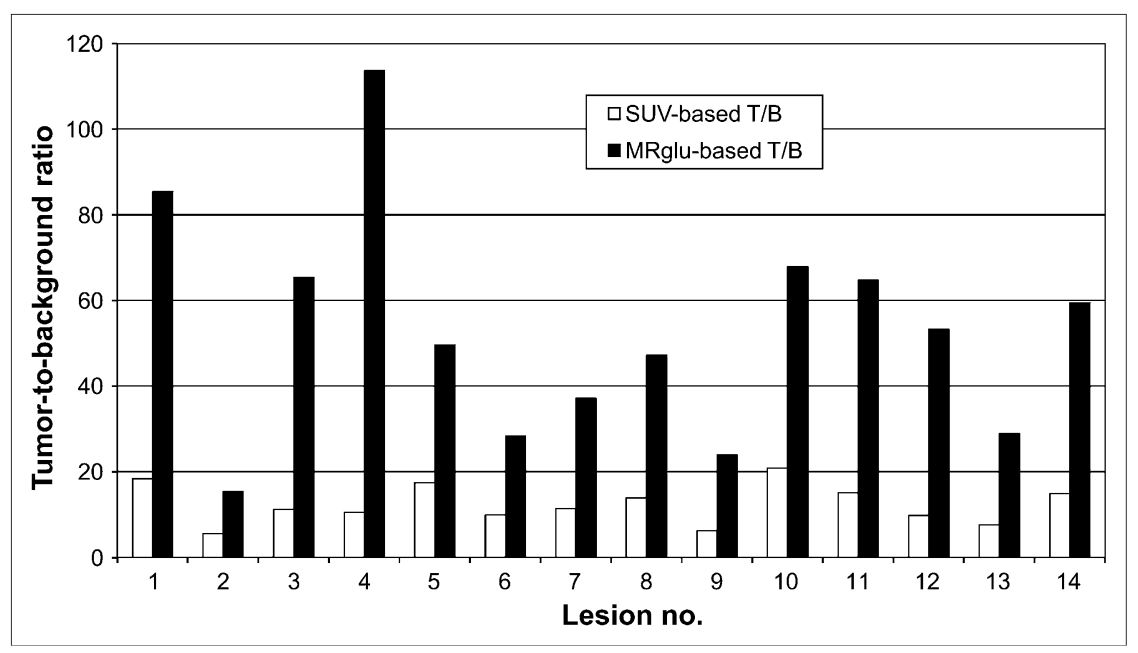




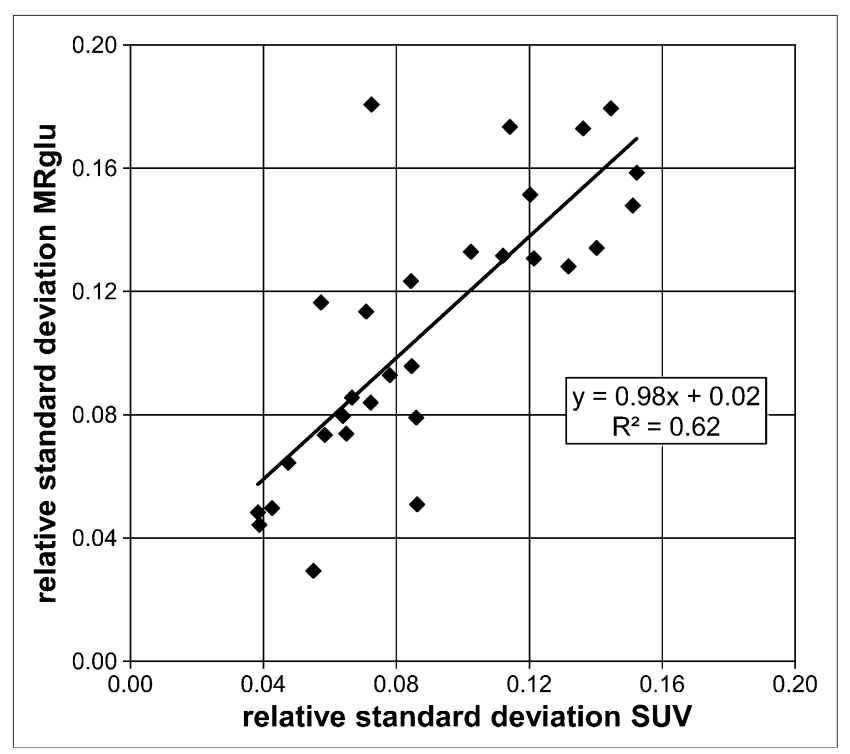

FIGURE 4. Relative SD of voxel clusters around tumor maxima in SUV maps and $\mathrm{MR}_{\text {glu }}$ maps for the 29 lesions investigated. Straight line is linear fit to data points.

also show significant size differences (Table 1). The application of partial-volume corrections, however, was outside the scope of this study.

In the "Materials and Methods" section, the question was raised of whether differences in statistical fluctuations of SUV and $\mathrm{MR}_{\text {glu }}$ maxima might cause the observed differences in tumor volumes. Because the average values of relative SD for SUV and $\mathrm{MR}_{\mathrm{glu}}$ are almost equal (0.090 and 0.108 , respectively), these fluctuations are of the same order of magnitude and cannot account for the overall differences in tumor volumes. This is also seen in Figure 4, where the slope of the fitted straight line is close to 1 and the offset is close to 0 .

The smaller $\mathrm{MR}_{\mathrm{glu}}$-based tumor volumes, as compared with SUV-based volumes, are in accordance with the findings of Daisne et al. (16). As far as we know, this study has been the only one in which ${ }^{18} \mathrm{~F}-\mathrm{FDG}$ PET, CT, and MRI-based tumor volumes were compared with path-

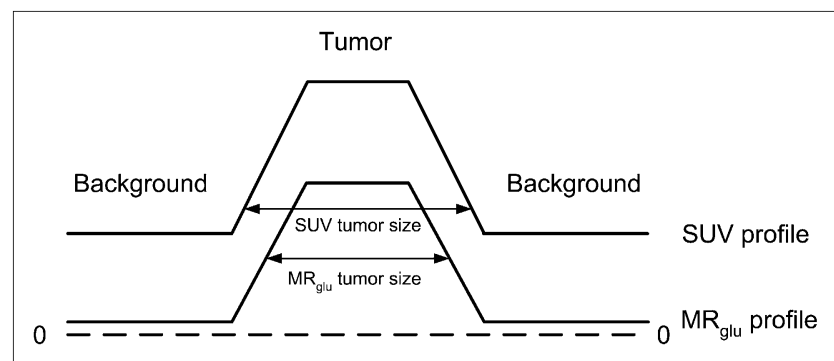

FIGURE 5. Simplified cross sections of tumor for SUV and $M_{\mathrm{glu}}$. SUV tumor profile is chosen to be superimposed on relatively high background signal, whereas $M_{\text {glu }}$ profile has low or negligible background. Tumor sizes, indicated by arrows, are based on $50 \%$ of lesion value. ologic findings of resection specimens. The investigators concluded that all 3 imaging modalities overestimated the real tumor sizes but that the PET estimation was closest to the true tumor volume. However, in this study only static PET was used, and tumor contouring was done on uptake images. In our retrospective study, a comparison with pathologic findings was unfortunately not possible. However, as mentioned before, $\mathrm{MR}_{\mathrm{glu}}$ images are expected to be more representative of the tumor metabolic activity and more reproducible than are SUV images. Therefore, our findings could be of relevance for radiation therapy planning and response evaluation.

It may be argued that dynamic PET protocols are less suitable for routine clinical application because of the longer scanning times and the necessity of arterial blood sampling, which can be too much of a burden to the patient. Although the dynamic scanning protocol in our study lasted $20 \mathrm{~min}$ for the transmission scan and $50 \mathrm{~min}$ for the emission scan, these scanning times can be reduced considerably. Our investigations were done on a PET scanner in 2-dimensional acquisition mode (septa extended) using bismuth germanate crystals and ${ }^{68} \mathrm{Ge}$ transmission scans. On modern PET/CT scanners with more sensitive lutetium oxyorthosilicate or lutetium yttrium silicon dioxide detection crystals in septa-less 3-dimensional acquisition mode with $\mathrm{CT}$ attenuation correction, the total scanning time can typically be reduced by a factor of 3-6 while retaining the same image quality. However, the lower limit on the scan duration is naturally imposed by the linear approximation in the Patlak analysis to calculate $\mathrm{MR}_{\text {glu }}$ values. In the present work on non-small cell lung carcinoma, this approximation was found to be valid after $10-15 \mathrm{~min}$ after injection, in accordance with the results of Hoekstra et al. (17). The implication is that on modern PET/CT scanners, $\mathrm{MR}_{\mathrm{glu}}$ values can reliably be determined using dynamic ${ }^{18}$ F-FDG PET scans of 20- to 25-min duration, including the time required for the CT scan. Although the plasma input functions in the present study were obtained by arterial sampling, for non-small cell lung cancer they can also be derived from the PET images using large bloodpool regions such as the aorta or the left ventricle of the heart (18).

\section{CONCLUSION}

Tumor volumes from ${ }^{18} \mathrm{~F}$-FDG $\mathrm{MR}_{\mathrm{glu}}$ maps were significantly smaller than SUV-based volumes. These findings can be clinically relevant for PET-based radiotherapy planning and therapy response monitoring.

\section{REFERENCES}

1. Ashamalla H, Guirgius A, Bieniek E, et al. The impact of positron emission tomography/computed tomography in edge delineation of gross tumor volume for head and neck cancers. Int J Radiat Oncol Biol Phys. 2007;68:388-395.

2. Biehl KJ, Kong FM, Dehdashti F, et al. ${ }^{18}$ F-FDG PET definition of gross tumor volume for radiotherapy of non-small cell lung cancer: is a single standardized uptake value threshold approach appropriate? J Nucl Med. 2006;47:1808-1812. 
3. Ceresoli GL, Cattaneo GM, Castellone P, et al. Role of computed tomography and $\left[{ }^{18} \mathrm{~F}\right]$ fluorodeoxyglucose positron emission tomography image fusion in conformal radiotherapy of non-small cell lung cancer: a comparison with standard techniques with and without elective nodal irradiation. Tumori. 2007;93: 88-96.

4. Gondi V, Bradley K, Mehta M, et al. Impact of hybrid fluorodeoxyglucose positron-emission tomography/computed tomography on radiotherapy planning in esophageal and non-small-cell lung cancer. Int J Radiat Oncol Biol Phys. 2007;67:187-195.

5. Gregoire V, Haustermans K, Geets X, Roels S, Lonneux M. PET-based treatment planning in radiotherapy: a new standard? J Nucl Med. 2007;48(suppl 1):68S$77 \mathrm{~S}$.

6. Grills IS, Yan D, Black QC, Wong CY, Martinez AA, Kestin LL. Clinical implications of defining the gross tumor volume with combination of CT and ${ }^{18}$ FDG-positron emission tomography in non-small-cell lung cancer. Int J Radiat Oncol Biol Phys. 2007;67:709-719.

7. Deniaud-Alexandre E, Touboul E, Lerouge D, et al. Impact of computed tomography and ${ }^{18} \mathrm{~F}$-deoxyglucose coincidence detection emission tomography image fusion for optimization of conformal radiotherapy in non-small-cell lung cancer. Int J Radiat Oncol Biol Phys. 2005;63:1432-1441.

8. Moureau-Zabotto L, Touboul E, Lerouge D, et al. Impact of CT and ${ }^{18} \mathrm{~F}-$ deoxyglucose positron emission tomography image fusion for conformal radiotherapy in esophageal carcinoma. Int J Radiat Oncol Biol Phys. 2005; 63:340-345.

9. Patel DA, Chang ST, Goodman KA, et al. Impact of integrated PET/CT on variability of target volume delineation in rectal cancer. Technol Cancer Res Treat. 2007;6:31-36.
10. Patlak CS, Blasberg RG. Graphical evaluation of blood-to-brain transfer constants from multiple-time uptake data: generalizations. J Cereb Blood Flow Metab. 1985;5:584-590.

11. Wienhard K. Measurement of glucose consumption using $\left[{ }^{18} \mathrm{~F}\right]$ fluorodeoxyglucose. Methods. 2002;27:218-225.

12. de Geus-Oei LF, van der Heijden HF, Visser EP, et al. Chemotherapy response evaluation with ${ }^{18} \mathrm{~F}-\mathrm{FDG}$ PET in patients with non-small cell lung cancer. $J$ Nucl Med. 2007;48:1592-1598.

13. Greuter HN, Boellaard R, van Lingen A, Franssen EJ, Lammertsma AA. Measurement of ${ }^{18} \mathrm{~F}$-FDG concentrations in blood samples: comparison of direct calibration and standard solution methods. J Nucl Med Technol. 2003;31:206-209.

14. Wienhard K, Eriksson L, Grootoonk S, Casey M, Pietrzyk U, Heiss WD. Performance evaluation of the positron scanner ECAT EXACT. J Comput Assist Tomogr. 1992;16:804-813.

15. Westerterp M, Pruim J, Oyen W, et al. Quantification of FDG PET studies using standardised uptake values in multi-centre trials: effects of image reconstruction, resolution and ROI definition parameters. Eur J Nucl Med Mol Imaging. 2007;34:392-404.

16. Daisne JF, Duprez T, Weynand B, et al. Tumor volume in pharyngolaryngeal squamous cell carcinoma: comparison at CT, MR imaging, and FDG PET and validation with surgical specimen. Radiology. 2004;233:93-100.

17. Hoekstra CJ, Hoekstra OS, Stroobants SG, et al. Methods to monitor response to chemotherapy in non-small cell lung cancer with ${ }^{18}$ F-FDG PET. J Nucl Med. 2002;43:1304-1309.

18. de Geus-Oei LF, Visser EP, Krabbe PF, et al. Comparison of image-derived and arterial input functions for estimating the rate of glucose metabolism in therapymonitoring ${ }^{18}$ F-FDG PET studies. J Nucl Med. 2006;47:945-949. 